of actually determining which is necessary. Thus no formally expressed relationship between stimulus and sensation has any validity ; but this does not prevent the commonly adopted logarithmic scales of intensity from having great practical value.

This discussion was continued by Dr. R. W. Pickford, Prof. H. Hartridge, Mr. F. H. Brittain and Mr. J. M. Waldram, of the Research Laboratories of the General Electric Co., Ltd., and Dr. M. H. Pirenne.

Dr. Pickford was not much inclined to believe that sensations are, in any literal sense, measurable ; but he gave illustrations to show that the commonly accepted correlations of stimulus and sensation variations are of operational value. In a written communication Dr. Pirenne expressed substantially the same view.

Prof. Hartridge showed that subjective observations carried out entirely independently by Granit and himself in the field of colour identification agreed remarkably closely, both in a qualitative sense and in regard to associated frequency values of the physical stimuli.

Mr. Brittain made an interesting suggestion of a physical model the operations of which might be regarded as strongly analogous to those of a human perceptual mechanism. This reinforced the view that no measure of input, or stimulus, could be valid which failed to pay attention to the character of the transforming and conducting processes internal to the responding system.

Mr. Waldram described some original and important illustrations of the use of stimulus-sensation correlations of a quantitative order.

Following this the discussion became general and open, and a large number of provocative and downright remarks were made. It is perhaps fair to say that there was exceedingly little agreement on any fundamental question, but almost complete agreement that even if sensations cannot be measured, they must be, and that the attempts which have been made are of great practical service.

In the afternoon meeting, the chair was taken by Dr. F. M. Lea, director of the Building Research Station (Department of Scientific and Industrial Research). The topic assigned was "The Subject as an Assessor of Sensation"; but the actual problems discussed concerned the methodology of experimental attempts to obtain reliable judgments based upon sensory evidence, and of their presentation in some numerical form, when the persons who make the judgments are also those who interpret the evidence.

Papirs were presented by Dr. D. Richards, of the General Post Office Engineering Department, on the "Design and Analysis of Subjective Acoustical Experiments which involve a Quantal Response"; by Dr. R. Harper and Dr. G. W. Scott Blair (National Institute of Dairying) on "The Subjective Assessment of Deformable Materials and of Food Products"; by Dr. R. G. Hopkinson (Building Research Station) on "The Multiple Criterion Technique of Subjective Appraisal", and by Dr. E. C. Bate-Smith and A. S. C. Ehrenberg (Low Temperature Research Station, Cambridge) on "The Operation of Laboratory Taste Panels".

The general discussion was opened by Dr. N. H. Mackworth, who was followed by a considerable number of other nominated speakers, and these by an open debate which was carried on with very great vigour.

In the course of the afternoon, almost all the known psycho-physical methods were described, and illus- trations of their alleged highly successful use were plentiful and varied. Dr. Hopkinson made a new and important point of method when he presented evidence to demonstrate that, if subjective judgments have to be made about the effects of a physical variable, more reliable results are secured if a limited number of criteria are used in succession instead of a single criterion.

Points arousing the greatest amount of difference of opinion were : $(a)$ In discrimination experiments, is it better to allot control of the physical variables to the subject, or to the experimenter, or to a third person? (b) Do threshold determinations, whether absolute or relative, throw any light upon subjective assessments of complex groups of stimuli ? (c) Do experts produce any better results from a general operational point of view than a random population, and are repeated experiments any better than a 'once-for-all' trial ?

Two questions received inadequate notice : (i) The suggestion, made by Dr. Mackworth, that whenever possible performance criteria should be made to supplement direct subjective assessment received. scant attention. This, in fact, is one form of the very difficult problem of the relationship between reliability and validation with which sooner or later everybody who makes use of subjective assessments must come to terms. But there was a persistent disposition to side-step this whole difficulty. (ii) The justification and types of statistical analysis and interpretation that are available, or should be considered, for dealing with arrays of data of the subjective assessment order were less considered than might have been expected.

In the end, Dr. Bate-Smith suggested that the conference seemed to be divided between those who say "You can't" and those who assert "We must". Perhaps, though he did not say so, he would favour some revision of the Emersonian dictum into a form such as :

When Theory whispers low "You can't" Practice replies "I must".

And that is what most people seemed to think. F. C. Bartlett

\section{BRITISH GELATINE AND GLUE RESEARCH ASSOCIATION \\ SECOND RESEARCH PANEL MEETING}

THE second meeting of the Research Panel of the British Gelatine and Glue Research Association, held at Beale's Restaurant, Holloway Road, London, N.7, on October 12, was attended by representatives of member firms, of research associations interested in the uses of gelatine and glue, and of the Department of Scientific and Industrial Research. The Research Panel meetings are intended to give an opportunity for interchange of scientific and technical information in the industry by the reading of papers followed by discussion.

In the morning session, Dr. J. H. Bowes, of the British Leather Manufacturers' Research Association, read a paper on "The Composition of Skin and the Changes Produced by the Action of Alkalis", describing, in the main, the work she has carried out in the past few years. Dr. Bowes first discussed the 
composition of skin, pointing out that, although collagen is the principal constituent, the remaining substances may have an important influence on the conversion of collagen to gelatin as well as on the tanning properties of the skin. Elastin fibres, reticular tissue, keratin, muscle fibres, sweat and sebaceous glands all occur, and, in addition, polysaccharides are present in small amounts.

Turning to the composition of collagen, Dr. Bowes reviewed the work which she, together with Prof. A. C. Chibnall and his collaborators, have done on the amino-acid composition of collagen. The collagen was specially prepared with minimum modification of the skin used. The results showed that almost the entire amino-acid composition is accounted for, and that cystine and tryptophan are absent. Dr. Bowes pointed out the relation between the titration curve obtained with collagen and its composition, and considered the modifications which occur when collagen is treated with alkali for prolonged periods. The most important reaction is the hydrolysis of the amide groups, with the production of ammonia. In addition, the swelling of collagen under alkaline conditions cannot be adequately interpreted unless a loss of cohesion is postulated. A lively discussion followed the paper.

The afternoon session consisted of a paper by the director of research of the Association, Mr. A. G. Ward, on "Recent Studies of High Polymers in Relation to the Properties of Gelatine and Glue". Mr. Ward described the methods which have enabled quantitative data to be obtained for high polymers. The importance of the non-uniformity of the molecular weight of gelatin was stressed, and the signi. ficance of the various forms of average molecular weight was discussed. Experimental methods were described which have been successfully applied to gelatin, including osmotic pressure, surface pressure and the ultracentrifuge. Further aspects of high polymers which were outlined were the theory of degradation of polymer chains and the origin of rubber-like elasticity. Results already obtained for gelatin by such workers as Scathard, Pouradier and Ferry were described.

\section{CHEMISTRY AT UNIVERSITY COLLEGE, DUNDEE}

$\mathrm{D}$ URING the past three years the Chemistry Department of University College, Dundee, has been enlarged, renovated and re-equipped. On October 23 the new building was formally opened by Lord Burghley, rector of the University of St. Andrews. Sir James Irvine, vice-chancellor and principal of the University of St. Andrews, introduced Prof. N. V. Sidgwick, formerly professor of chemistry in the University of Oxford, who delivered an address. After the ceremony, Lady Burghley laid the foundation stone of a new science building which will house the Department of Electrical Engineering and the Department of Botany at Dundee.

The original chemistry laboratory at Dundee was built in 1883. It followed the German nineteenthcentury style, having been modelled, like those of the Imperial College of Science and Technology, London, and of Owens College, Manchester, on Hofmann's laboratory at Bonn. At that time the Dundee laboratory ranked among the best-equipped in Great Britain, and was unique in -its air-conditioning system which had been designed by Thomas Carnelley, the first professor at Dundee, along lines which have now become standard engineering practice. The building was added to in 1888 , and the original plan was completed in 1905 . Apart from some internal renovation in 1925, the Department has remained largely unchanged for nearly fifty years.

A storey has now been added, and the whole building has been completely renovated and reserviced. The new floor provides two teaching laboratories, four organic chemistry research rooms and a glassblowers' workshop. The basement rooms vacated by the organic chemists have been converted to physical chemistry research laboratories. The two new teaching laboratories are each designed to accommodate thirty-two students comfortably ; one will be used for teaching organic chemistry to secondand third-year students, while the other is shared between inorganic and physical chemistry teaching at the same level. The servicing of the building has been renewed and now includes all the usual piped services (gas, hot and cold water, compressed air and live steam) with a selection of electrical services (415 V. three-phase A.C., 240 V. A.c., 240 V. D.c. and $50 \mathrm{~V}$. D.c.). The building is steam-heated and airconditioned throughout.

In addition to the rebuilding, the Department has been extensively re-equipped. The research facilities have been extended to cover most important modern techniques in both physical and organic chemistry with the object of enabling problems to be studied using several different experimental methods. The work of the laboratory is at present concentrated mainly on the thermodynamics of solutions and adsorbed phases, electrochemistry, free-radical reactions and their relevance in polymer chemistry, acid-base catalysis, stereochemistry and problems of optical activity, together with general problems of reactivity of organic molecules. Furthermore, a full range of optical and spectroscopic techniques will shortly be available to supplement purely thermodynamic messurements. A well-equipped workshop and glassblowers' shop are making important contributions to these developments. It can now be fairly claimed that University College, Dundee, has a Chemistry Department which, for its size, is again among the best-equipped in Great Britain.

A conversazione was held on the afternoon of October 23, followed by the formal opening. Visitors were able to see a variety of research work in progress, demonstrations of the experiments used in the teaching laboratories, and a series of lecture demonstration models. Lord Burghley and the other guests, including representatives of Scottish universities and chemical industry, and past students, were welcomed by Prof. D. H. Everett, who referred to the difficulties which had been overcome in carrying through the reconstruction while the laboratory was in full use for both teaching and research. In a few words Lord Burghley declared the renovated building open.

Prof. Sidgwick began his address by mentioning the past holders of the chair of chemistry in University College, Dundee, since the foundation of the chair in 1882. Thomas Carnelley was professor for only six years and would, had he lived, have risen to a very high position in science. Percy Faraday Frankland, who in the field of chemistry was the distinguished son of an even more distinguished father, held the chair in Dundee during 1888-94; he then moved to Birmingham-and, incidentally, built there a labor- 